\title{
Development of a bismuth-based metal-organic framework for photocatalytic hydrogen production
}

\author{
Yejun Xiao a,b, Xiangyang Guo a, Junxue Liuc, Lifang Liu a,b, Fuxiang Zhang a,*, Can Li a,\# \\ a State Key Laboratory of Catalysis, Dalian Institute of Chemical Physics, Chinese Academy of Sciences, Dalian National Laboratory for Clean Energy, the \\ Collaborative Innovation Center of Chemistry for Energy Materials (iChEM), Dalian 116023, Liaoning, China \\ b University of Chinese Academy of Sciences, Beijing 100049, China \\ c State Key Laboratory of Molecular Reaction Dynamics, the Collaborative Innovation Center of Chemistry for Energy Materials (iChEM), Dalian Institute \\ of Chemical Physics, Chinese Academy of Sciences, Dalian 116023, Liaoning, China
}

\section{A R T I C L E I N F}

\section{Article history:}

Received 20 December 2018

Accepted 8 February 2019

Published 5 September 2019

\section{Keywords:}

Metal-organic framework

Photocatalysis

Water reduction

Ligand-to-metal charge transfer

Charge separation

\begin{abstract}
A B S T R A C T
A novel 3D bismuth-organic framework (called Bi-TBAPy) single crystal was synthesized by employing 1,3,6,8-tetrakis(p-benzoic acid)pyrene ( $\mathrm{H}_{4}$ TBAPy) as an organic linker. The study demonstrates that the Bi-TBAPy not only possesses good chemical stability and suitable band edge positions for promising photocatalytic $\mathrm{H}_{2}$ evolution, but it also exhibits a typical ligand-to-metal charge transfer for favorable charge separation. The photocatalytic $\mathrm{H}_{2}$ evolution rates on the as-obtained Bi-TBAPy with different cocatalysts modified were examined with triethanolamine as the sacrificial reagent. Based on this, the hydrogen evolution rate of $140 \mu \mathrm{mol} \mathrm{h}^{-1} \mathrm{~g}^{-1}$ was obtained on the optimized sample with a loading of $2 w t \% \mathrm{Pt}$ as a cocatalyst. To the best of our knowledge, this is the first bismuth-based metal-organic framework (MOF) that functions as an effective photocatalyst for photocatalytic water reduction. Our study not only adds a new member to the family of photocatalyst materials, but also reveals the importance of cocatalyst modification in improving photocatalytic activity of MOFs.
\end{abstract}

(C) 2019, Dalian Institute of Chemical Physics, Chinese Academy of Sciences. Published by Elsevier B.V. All rights reserved.
Metal-organic frameworks (MOFs) composed of metal-oxo clusters and polydentate organic linkers represent an intriguing class of porous crystalline material with many attractive properties such as porosity, large surface area, and structural and functional tunability [1]. Because of these unique advantages, MOFs have been widely investigated for gas storage and separation, sensors, drug delivery, and catalysis [2]. Some photo-responsive MOFs exhibiting semiconductor behavior have been developed as photocatalysts for promising solar energy conversion. In particular, solar-driven water splitting is of great significance when considering that hydrogen evolution from water provides an environmentally friendly and sustainable alternative to fossil fuels [3].

To date, some MOF-based photocatalysts have been explored for hydrogen production. These contain UiO-66 [4], $\mathrm{NH}_{2}$-UiO-66 [4], $\mathrm{NH}_{2}$-MIL-125(Ti) [5], and Al-PMOF [6]. Although major progress has been achieved, the selection of metals is often confined based on the robustness and conduction band (CB) position of the as-obtained MOF material [7,8]. Consequently, new photo-responsive MOFs composed of other metals with good robustness and a suitable band structure are desired. Bismuth, as a nontoxic and earth-abundant element, is

\footnotetext{
* Corresponding author. Tel: +86-411-82463370; E-mail: fxzhang@dicp.ac.cn

\# Corresponding author. Tel: +86-411-84379070; Fax: +86-411-84694447; E-mail: canli@dicp.ac.cn

This work was supported by the National Natural Science Foundation of China (21633009, 21522306, 21633010), DICP\&QIBEBT (UN201805), and the Dalian Science Foundation for Distinguished Young Scholars (2017RJ02).
}

DOI: S1872-2067(19)63329-2 | http://www.sciencedirect.com/science/journal/18722067 | Chin. J. Catal., Vol. 40, No. 9, September 2019 
a promising candidate for the construction of stable MOFs, as it has a relatively high valence state and flexible coordination geometry $[9,10]$. However, the synthesis of bismuth-based MOFs remains challenging because of their structural sensitivity to the reaction conditions such as solvents, temperature, and reaction time. The complicated structural behavior of $\mathrm{Bi}^{3+}$ ions during the solvothermal synthesis makes controlling the process of crystal growth difficult [11]. Consequently, reports on the synthesis of bismuth-based MOFs with photocatalytic activity are limited [12-14]. To the best of our knowledge, no bismuth-based MOFs have been synthesized for photocatalytic water reduction.

In this study, we report on a new stable bismuth-organic framework (Bi-TBAPy) with a 3D framework structure by employing 1,3,6,8-tetrakis(p-benzoic acid)pyrene (H4TBAPy) as the organic linker. The as-obtained Bi-TBAPy is demonstrated to possess good stability and suitable band edge positions for photocatalytic water reduction. Based on our optimization, Bi-TBAPy exhibits the optimal $\mathrm{H}_{2}$ evolution rate of $140 \mu \mathrm{mol}$ $\mathrm{h}^{-1} \mathrm{~g}^{-1}$ when triethanolamine (TEOA) is used as the sacrificial reagent, demonstrating its promising future in solar fuel production.

The structure of a Bi-TBAPy single crystal was investigated by single-crystal X-ray diffraction (XRD) analysis, and details of the crystal structure and refinement data are provided in Table S1. As given in Fig. S1, the Bi-TBAPy is crystallized in monoclinic space group $\mathrm{C} 2 / \mathrm{c}$ to form a $3 \mathrm{D}$ rod-like structure. The typical structure is introduced in Fig. 1(a), where the Bi atom is coordinated with eight oxygen atoms from four linkers with a bond length of $\sim 2.435 \AA$. A dimethylamine cation serving as the counter ion is also coordinated with the $\mathrm{Bi}$ atom to maintain the charge balance, and the bond length of $\mathrm{Bi}-\mathrm{N}$ is $\sim 2.923 \AA$. Each TBAPy ${ }^{4-}$ linker coordinated to four bismuth centers shapes the backbone of Bi-TBAPy into a 3D framework (Fig. 1(b) and (c)). Two types of 1D channels with different shapes exist along the $a$ axis (Fig. 1(c)). One channel has a rhomboid shape and is occupied by dioxane; the other has a quadrilateral shape and is occupied by dimethylamine solvent molecules. The length of the two sides of these two windows are both 7.37 $\times 11.65 \AA^{2}$, although their shapes are different. The total solvent-accessible volume is approximately $8.4 \%$ upon solvent removal, which is calculated with PLATON software [15]. The BET surface area of Bi-TBAPy is measured to be $594 \mathrm{~m}^{2} \mathrm{~g}^{-1}$. The coordination effect between Bi ions and $\mathrm{H}_{4}$ TBAPy linkers can be further confirmed by the results of FT-IR measurement (Fig. S2), where the hydroxyl vibration peak of $-\mathrm{COOH}$ in the range of 3000-3400 $\mathrm{cm}^{-1}$ disappears during the shift of the carbonyl vibration peak in the range of $1620-1750 \mathrm{~cm}^{-1}$. The experimental XRD pattern (Fig. 1(d)) of Bi-TBAPy conforms well with the simulated pattern, which is generated based on single crystal structure analysis, thus demonstrating a good phase purity of the bulk material.

To examine the physical and/or chemical stability of Bi-TBAPy, thermogravimetric analysis (TGA) was first conducted, with results given in Fig. S3. The results reveal that the Bi-TBAPy exhibits good thermal stability with the framework a)

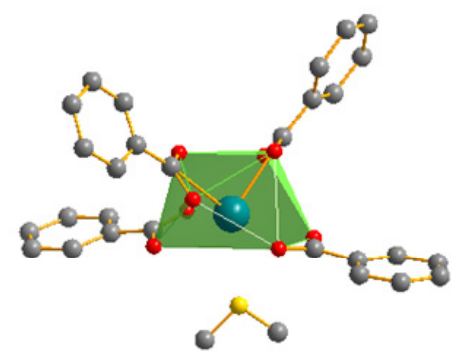

b)

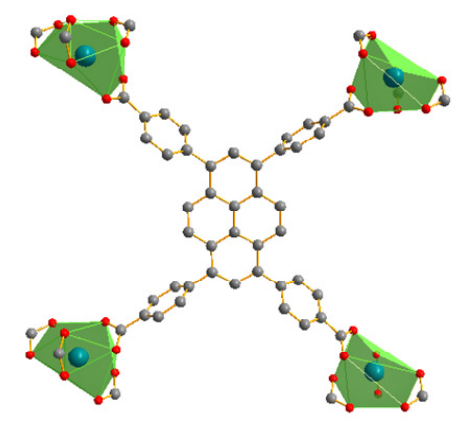

c)

d)
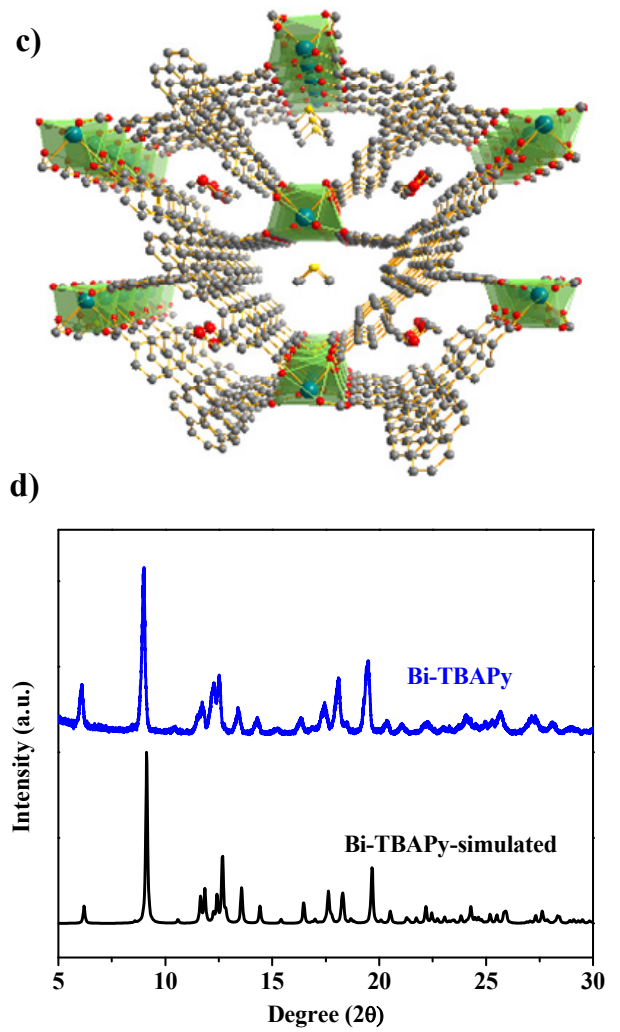

Fig. 1. Structure and analysis of Bi-TBAPy. (a) Coordination mode of the Bi atom in Bi-TBAPy; (b) coordination mode of the TBAPy moiety in Bi-TBAPy; (c) crystal structure of Bi-TBAPy viewed along the $a$ axis; (d) XRD patterns of Bi-TBAPy and Bi-TBAPy-simulated. Color representations: red, O; yellow, N; gray, C; green, Bi. H atoms are removed for clarity. 
collapsed at approximately $350^{\circ} \mathrm{C}$. Subsequently, the Bi-TBAPy sample was also demonstrated to have good solvent stability when considering the fact that no obvious change of XRD patterns could be observed in the samples before and after impregnation in water, DMF, dioxane, acetonitrile, methylene dichloride, or isopropanol for $12 \mathrm{~h}$ at room temperature (Fig. S4). On the whole, the as-obtained Bi-TBAPy sample has an unexpected thermal and solvent stability, demonstrating its good potential as a photocatalyst.

Fig. 2(a) shows its typical UV/vis DRS, based on which the Bi-TBAPy has a visible light response with an absorption edge of $c a .465 \mathrm{~nm}$. The band gap of Bi-TBAPy was then estimated to be $c a .2 .67 \mathrm{eV}$ from the Kubelka-Munk function. To evaluate further the band edge positions of Bi-TBAPy, a Mott-Schottky measurement was conducted. Fig. 2(b) clearly reveals the n-type semiconductor property of Bi-TBAPy, and the flat band potential was calculated to be $c a .-0.15 \mathrm{~V} v$ s. RHE. As the bottom of the $\mathrm{CB}$ of an n-type semiconductor is generally more negative by $c a .0 .1 \mathrm{eV}$ than the flat band potential [16], the $\mathrm{CB}$ of Bi-TBAPy was estimated to be $c a .-0.25 \mathrm{eV}$. Together with the bandgap value estimated from the UV/vis DRS (Fig. 2(a)), the valence band (VB) was thus determined to be located at $2.42 \mathrm{eV}$. The estimated band edge positions of Bi-TBAPy are shown in the insert of Fig. 2(b), in which the CB exhibits sufficient potential in the water reduction process.

Encouraged by the good stability and suitable CB position of Bi-TBAPy, we examined the performance of Bi-TBAPy for water reduction by using TEOA as the hole scavenger. The photocatalytic water reduction activity of the Bi-TBAPy sample free of a cocatalyst was very low (Fig. S5). As shown in Fig. 2(c), the loading of a suitable cocatalyst is desired to promote the $\mathrm{H}_{2}$ evolution rate, and the platinum modified sample appeared to
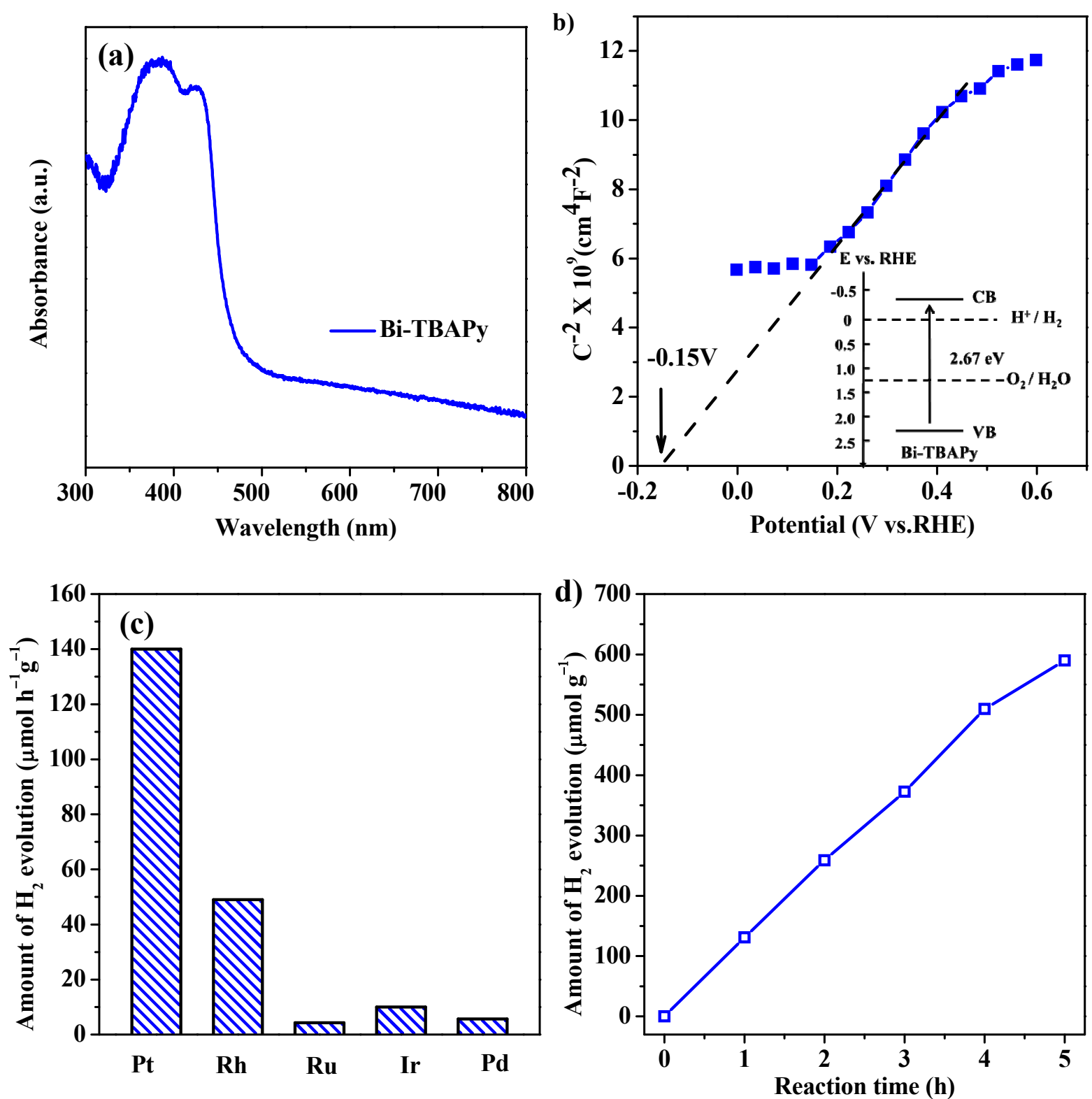

Fig. 2. (a) UV/Vis diffuse reflectance spectra of Bi-TBAPy; (b) Mott-Schottky plot of the Bi-TBAPy electrode and the estimated band edge positions of Bi-TBAPy (insert). Electrolyte: $0.05 \mathrm{~mol} / \mathrm{L}$ phosphate buffer solution $(\mathrm{PH}=6.0)$; (c) effect of typical reduction cocatalysts $(2$ wt $\%)$ on the photocatalytic $\mathrm{H}_{2}$ evolution rate of Bi-TBAPy; (d) time course of photocatalytic $\mathrm{H}_{2}$ evolution on 2 wt $\%$ Pt/Bi-TBAPy. 
promote the $\mathrm{H}_{2}$ evolution rate most efficiently. The difference in the promotion effect originating from the cocatalyst species may derive from their distinct ability at trapping electrons from the CB of Bi-TBAPy and/or activating protons for $\mathrm{H}_{2}$ evolution [17]. A volcanic-type curve of $\mathrm{H}_{2}$ evolution dependence on the $\mathrm{Pt}$ content was observed (Fig. S5), and the optimal $\mathrm{H}_{2}$ evolution rate of $140 \mu \mathrm{mol} \mathrm{h}^{-1} \mathrm{~g}^{-1}$ appeared for the sample with $2.0 w t \%$ Pt loaded. The XPS pattern of Bi-TBAPy after hydrogen evolution verified the loading of metallic Pt based on the binding energies of Pt $4 f_{7 / 2}$ and Pt $4 f_{5 / 2}$ peaks, as shown in Fig. S6 [18]. The loading of a suitable amount of platinum could trap the photogenerated electrons and accelerate the conversion of water molecules, whereas an excess amount probably leads to the shielded light absorption of MOFs, thus resulting in decreased photocatalytic $\mathrm{H}_{2}$ evolution performance. For comparison, the water reduction performance of $2 w t \% \mathrm{Pt} / \mathrm{H}_{4} \mathrm{TBAPy}$ was also examined under the same conditions as the $2 w t \%$ Pt/Bi-TBAPy. The negligible hydrogen evolution indicates that the formation of a framework by incorporating $\mathrm{Bi}$ ions is vital to the photocatalytic performance of Bi-TBAPy. The typical time course of the photocatalytic water reduction on the optimized sample is shown in Fig. 2(d), in which the linear increase of $\mathrm{H}_{2}$ evolution as a function of the reaction time demonstrates the good photochemical stability of Bi-TBAPy. In addition, the XRD patterns of Bi-TBAPy before and after $\mathrm{H}_{2}$ evolution were not obviously altered (Fig. S7), also indicating the good stability of Bi-TBAPy during the photocatalytic reaction. Furthermore, the transient photocurrent response on the Bi-TBAPy photoelectrode in a three-electrode setup was conducted by using a 0.5 -M sodium sulfate solution as an electrolyte solution. An obvious photocathode current could be observed from the chopped photocurrent profile of Bi-TBAPy (Fig. S8), indicating the generation of electron-hole pairs in Bi-TBAPy during light irradiation and the capacity for photoelectrochemical water reduction by photoinduced electrons.

To obtain insights into the mechanism of the charge transfer during the photocatalytic process, $\mathrm{Bi} 4 f$ XPS patterns of Bi-TBAPy before and after $\mathrm{H}_{2}$ evolution were measured and compared. As shown in Fig. 3(a), in addition to the characteris-

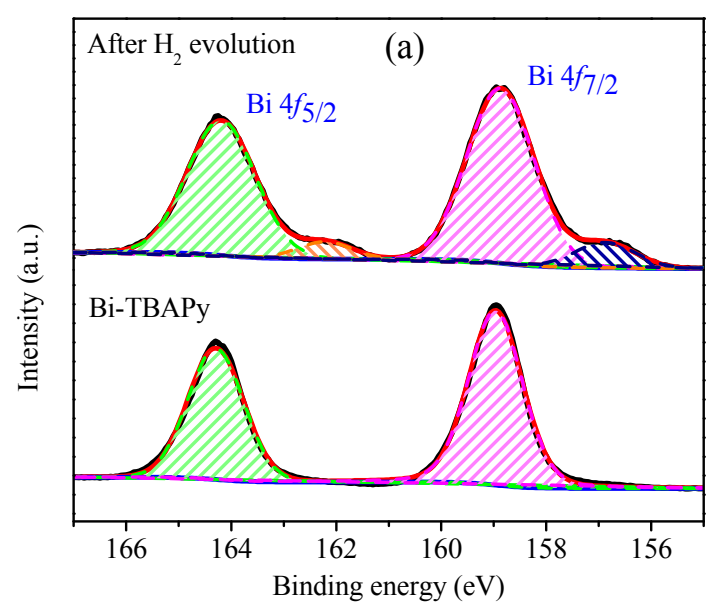

tic peaks of $\mathrm{Bi}^{3+}$ ions located at 164.2 and $158.9 \mathrm{eV}$, two new peaks centered at 162.2 and $156.9 \mathrm{eV}$ were deconvoluted after $3 \mathrm{~h}$ of irradiation and were consistent with the characteristic peaks of the lower valence state of the Bi ion $[19,20]$. It should be noted that although the lower valence state of $\mathrm{Bi}$ ions was generated, the framework of Bi-TBAPy was well maintained based on the XRD patterns shown in Fig. S7, indicating the robustness of Bi-TBAPy. Based on the XPS analysis, a ligand-to-metal charge transfer (LMCT) process was observed to occur in Bi-TBAPy, where the photogenerated electrons transferred from the excited TBAPy group to $\mathrm{Bi}^{3+}$, resulting in partial reduction of bismuth ions. The LMCT mechanism is always observed for MOFs as photocatalysts because of the intrinsic charge separation process. As a result, steady-state photoluminescence (PL) measurements were conducted to evaluate the influence of this charge transfer process. The results are shown in Fig. 3(b). $\mathrm{H}_{4}$ TBAPy exhibits the strongest steady-state PL intensity, revealing that a great carrier recombination process occurs in organic linkers, and the construction of Bi-TBAPy could suppress this process, thus resulting in decreased PL intensity of pristine Bi-TBAPy. Compared to the pristine sample, the considerably diminished steady-state PL intensity of Bi-TBAPy after irradiation confirmed the separation of photoinduced carriers as a result of the LMCT process, which in turn inhibited the process of charge recombination. The proposed mechanism for photocatalytic $\mathrm{H}_{2}$ over Bi-TBAPy is illustrated in Fig. 4. First, the TBAPy groups in Bi-TBAPy absorb light to generate electrons and holes. Then, the excited electrons can be utilized through two pathways. In one pathway, electrons first transfer to the near $\mathrm{Bi}^{3+}$ ions by following the LMCT mechanism and then transfer to the cocatalysts. In the other pathway, the excited electrons in TBAPy groups transfer directly to Pt particles. Subsequently, the deposited Pt act as active sites to perform the catalytic reduction of water while the photogenerated holes are simultaneously consumed by the sacrificial reagent TEOA.

In summary, we synthesized a novel 3D bismuth-organic framework (Bi-TBAPy) with good stability and suitable band edge positions for promising photocatalytic $\mathrm{H}_{2}$ evolution. The

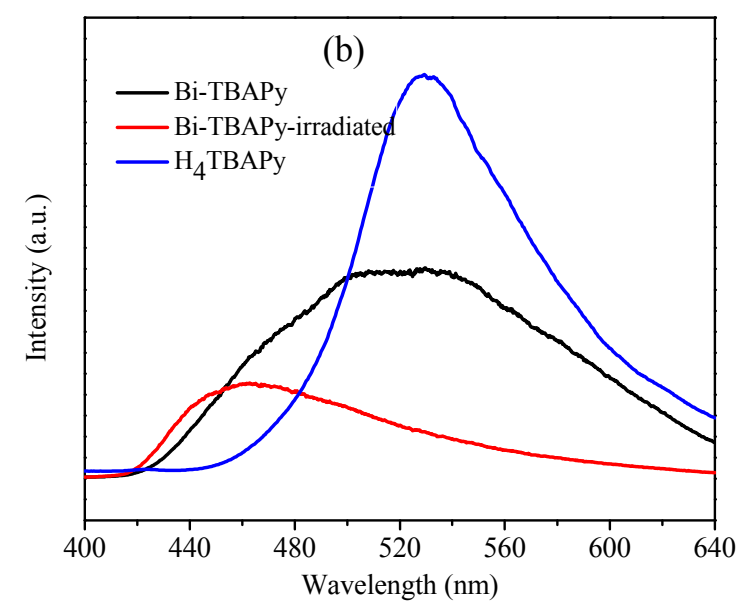

Fig. 3. Characterizations of typical samples. (a) Bi $4 f$ XPS spectra of Bi-TBAPy and Bi-TBAPy after $\mathrm{H}_{2}$ evolution; (b) steady-state emission spectra of Bi-TBAPy, Bi-TBAPy-irradiated, and $\mathrm{H}_{4}$ TBAPy. 


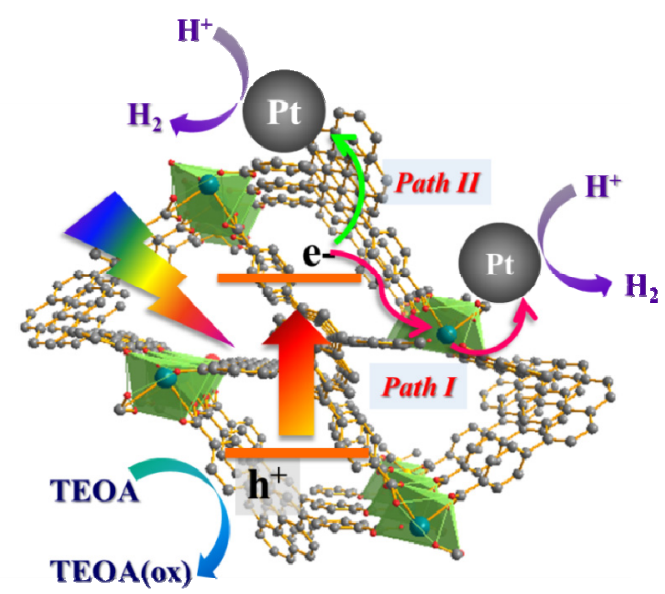

Fig. 4. Proposed mechanism of photocatalytic $\mathrm{H}_{2}$ evolution over Bi-TBAPy.

influence of cocatalysts and the amount of loading on the performance of water reduction were investigated and discussed, and the optimal $\mathrm{H}_{2}$ evolution rate of $140 \mu \mathrm{mol} \mathrm{h}^{-1} \mathrm{~g}^{-1}$ was obtained. The LMCT mechanism that occurred in Bi-TBAPy during the photocatalytic process was confirmed by XPS spectra, and this intrinsic charge separation process was favorable to the photocatalytic reactions because the charge recombination was suppressed. Our study not only adds a new member to the family of MOF material, it also offers new insights into the design and manipulation of MOFs for applications in photocatalytic water splitting.

\section{Acknowledgments}

This work was financially supported by National Natural Science Foundation of China (21633009, 21522306, 21633010), jointed project between DICP and QIBEBT(UN201805), and Dalian Science Foundation for Distinguished Young Scholars (2017RJ02). F. Zhang thanks the priority support from the "Hundred Talents Program" of Chinese Academy of Sciences.

\section{References}

[1] H. Furukawa, K. E. Cordova, M. O'Keeffe, O. M. Yaghi, Science, 2013, $341,1230444$.

[2] P. Silva, S. M. F. Vilela, J. P. C. Tomébc, F. A. Almeida Paz, Chem. Soc. Rev., 2015, 44, 6774-6803.

[3] Y. X. Fang, Y. W. Ma, M. F Zheng, P. J. Yang, A. M. Asiri, X. C. Wang, Coord. Chem. Rev., 2018, 373, 83-115.

[4] C. G. Silva, I. Luz, F. X. Llabrési Xamena, A. Corma, H. García, Chem. Eur. J., 2010, 16, 11133-11138.

[5] Y. Horiuchi, T. Toyao, M. Saito, K. Mochizuki, M. Iwata, H. Higashimura, M. Anpo, M. Matsuoka, J. Phys. Chem. C, 2012, 116, 20848-20853.

[6] A. Fateeva, P. A. Chater, C. P. Ireland, A. A. Tahir, Y. Z. Khimyak, P. V. Wiper, J. R. Darwent, M. J. Rosseinsky, Angew. Chem. Int. Ed., 2012, 51, 7440-7444.

[7] J. D. Xiao, L. L. Han, J. Luo, S. H. Yu, H. L. Jiang, Angew. Chem. Int. Ed., 2018, 57, 1103-1107.

[8] S. Yuan, L. Feng, K. C. Wang, J. D. Pang, M. Bosch, C. Lollar, Y. J. Sun, J. S. Qin, X. Y. Yang, P. Zhang, Q.Wang, L. F. Zou, Y. M. Zhang, L. L. Zhang, Y. Fang, J. L. Li, H. C. Zhou, Adv. Mater., 2018, 30, 1704303.

\section{Graphical Abstract}

Chin. J. Catal., 2019, 40: 1339-1344 doi: S1872-2067(19)63329-2

\section{Development of a bismuth-based metal-organic framework for photocatalytic hydrogen production}

Yejun Xiao, Xiangyang Guo, Junxue Liu, Lifang Liu, Fuxiang Zhang*, Can Li*

Dalian Institute of Chemical Physics, Chinese Academy of Sciences; University of Chinese Academy of Sciences
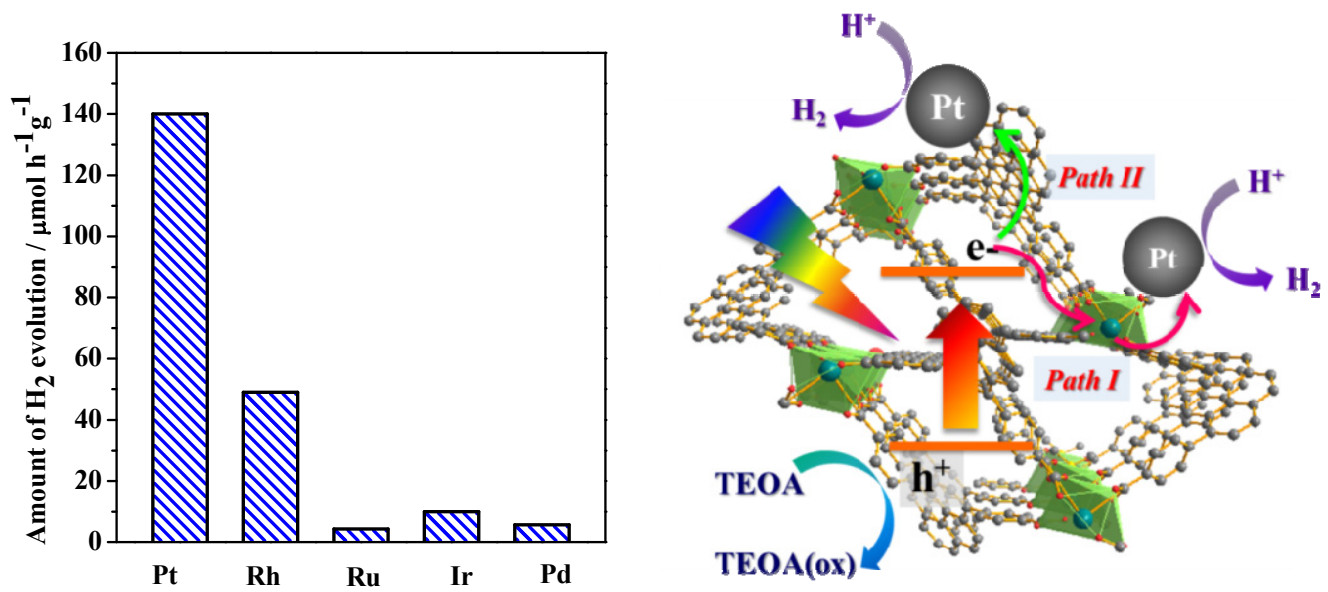

A new 3D bismuth-organic framework (Bi-TBAPy) with ligand-to-metal charge transfer (LMCT) process was synthesized to exhibit for the first time robust photocatalytic water reduction, demonstrating its promising future in solar energy conversion. 
[9] A. Thirumurugan, A. K. Cheetham, Eur. J. Inorg. Chem., 2010, 3823-3828.

[10] B. Y. Xu, Y. An, Y. Y. Liu, B. B. Huang, X. Y. Qin, X. Y. Zhang, Y. Da, M. H. Whangbo, Chem. Commun., 2016, 52, 13507-13510.

[11] M. Köppen, A. Dhakshinamoorthy, A. K. Inge, O. Cheung, J. Ångstrilanöm, P. Mayer, N. Stock, Eur. J. Inorg. Chem., 2018, 30, 3496-3503.

[12] Y. J. Kong, L. J. Han, L. T. Fan, F. Z. Kong, X. Zhou, J. Fluorine Chem., 2016, 186, 40-44.

[13] G. Z. Wang, Y. Y. Liu, B. B. Huang, X. Y. Qin, X. Y. Zhang, Y. Dai, Dalton Trans., 2015, 44, 16238-16241.
[14] G. Z. Wang, Q. L. Sun, Y. Y. Liu, B. B. Huang, Y. Dai, X. Y. Zhang, X. Y. Qin, Chem. Eur. J., 2015, 21, 2364-2367.

[15] A. L. Spek, J. Appl. Crystallogr., 2003, 36, 7-13.

[16] Y. Matsumoto, J. Solid State Chem., 1996, 126, 227-234.

[17] J. H. Yang, D. E Wang, H. X. Han, C. Li, Acc. Chem. Res., 2013, 46, 1900-1909.

[18] E. A. Carbonio, M. J. Prieto, A. Siervo, R. Landers, J. Phys. Chem. C, 2014, 118, 28679-28688.

[19] B.R. Sekhar, N.L. Saini, P. Srivastava, K.B. Garg, J. Phys. Chem. Solids, 1994, 55, 49-58.

[20] B. Afsin, M.W. Roberts, Spectrosc. Lett., 1994, 27, 139-146.

\title{
新型铋基金属有机框架的合成及其光催化产氢性能
}

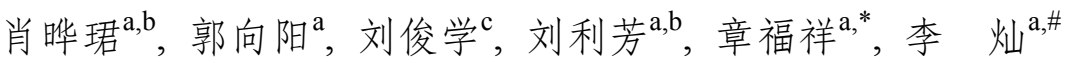 \\ a 中国科学院大连化学物理研究所, 催化基础国家重点实验室, 洁净能源国家实验室, \\ 能源材料化学协同创新中心, 辽宁大连 116023 \\ $\mathrm{b}$ 中国科学院大学, 北京 100049 \\ ${ }^{\mathrm{c}}$ 中国科学院大连化学物理研究所, 分子反应动力学国家重点实验室, 能源材料化学协同创新中心, 辽宁大连 116023
}

\begin{abstract}
摘要: 金属有机框架材料(MOFs)是由金属离子或团簇与多齿有机配体配位结合形成的一种结晶性材料. 因其具有三维孔 道结构, 以及比表面积大、结构和功能可调变等优点, 在气体的储存与分离、传感、药物传输和催化领域等方面具有广泛 的应用. 近年来, MOFs材料因其独特的结构和可调变性, 在太阳能转化领域逐渐崭露头角, 其中光催化水分解制氢作为一 种可行的太阳能光化学转化方法, 引起了人们的广泛关注. 目前, MOFs材料用于光催化水分解制氢的研究已经取得了一 定的进展, 但在合成新型具有光催化性能的MOFs材料时, 考虑到材料稳定性和能带位置的要求, 在金属离子选择上往往受 到限制. 铋元素无毒且储量丰富, 因其具有较高的价态和灵活的配位模式, 在构建MOFs材料时常常会表现出独特的优势. 然而, 铋基MOFs 对于合成条件十分敏感, $\mathrm{Bi}^{3+}$ 离子复杂的配位模式也使晶体结晶的过程难以调控. 因此, 铋基MOFs在合成 方面具有一定的挑战. 目前已报道的具有光催化活性的铋基MOFs材料十分有限, 且能够实现光催化水还原的铋基MOFs 材料还未有报道. 本文利用 1,3,6,8-四(4-羧基苯)萠( $\mathrm{H}_{4} \mathrm{TBAPy}$ )作为有机配体, 合成了一种新型的三维铋基MOFs单晶材料 (记为“Bi-TBAPy”), 并对其结构、稳定性、光催化水还原性能及电荷转移机理进行了研究.

单晶衍射结果表明, Bi-TBAPy中铋离子与来自四个不同配体的八个氧原子配位形成了立体的三维结构, 二甲胺阳离 子作为抗衡离子与铋离子配位使整个骨架保持电中性. 实验测得的XRD结果与模拟的一致, 表明Bi-TBAPy具有较高的相 纯度. TGA以及XRD测试分析也证明了Bi-TBAPy具有良好的热稳定性和化学稳定性. 结合UV/vis和莫特-肖特基的测试结 果可知, Bi-TBAPy具有 $n$ 型半导体性质, 带隙宽度约为 $2.67 \mathrm{eV}$, 导带和价带位置分别位于 -0.25 和 $2.42 \mathrm{eV}$, 表明Bi-TBAPy在 热力学上能够满足光催化水还原的要求. 随后, 以三乙醇胺为牺牲试剂考察了Bi-TBAPy的光催化产氢性能. 研究发现助 催化剂的种类对催化剂性能具有重要影响, 担载2 $w t \%$ Pt时表现出最优的产氢速率, 达 $140 \mu \mathrm{mol} \mathrm{h}^{-1} \mathrm{~g}^{-1}$, 其为目前报道的首 个具有光催化水还原性能的铋基MOFs催化剂. 长时间的光催化水还原反应测试可以持续稳定的进行, 同时反应前后 Bi-TBAPy的XRD也不发生变化, 表明该材料具有很好的光化学稳定性. 反应后样品的Bi $4 f$ XPS谱图表明反应过程中有低 价铋的生成, 这说明配体受激发产生的光生电荷能够转移到 $\mathrm{Bi}^{3+}$ 上使其部分被还原. 因此, 该材料能够实现配体-金属电荷 转移(LMCT)的过程, 荧光光谱测试的结果证实了该过程有利于光生载流子的分离.
\end{abstract}

关键词: 金属有机框架; 光催化; 水还原; 配体到金属电荷转移; 电荷分离

收稿日期: 2018-12-20. 接受日期: 2019-02-08. 出版日期: 2019-09-05.

*通讯联系人. 电话: (0411)82463370; 电子信箱: fxzhang@dicp.ac.cn

\#通讯联系人. 电话: (0411)84379070; 传真: (0411)84694447; 电子信箱: canli@dicp.ac.cn

基金来源：国家自然科学基金(21633009, 21522306, 21633010); 大连化物所与青岛能源所两所融合基金项目(UN201805); 大连杰 出青年科学基金(2017RJ02).

本文的电子版全文由Elsevier出版社在ScienceDirect上出版(http://www.sciencedirect.com/science/journal/18722067). 